\title{
Insights into Activation Mechanisms of Store-Operated TRPC1 Channels in Vascular Smooth Muscle
}

\author{
Miguel A. S. Martín-Aragón Baudel ${ }^{1}{ }^{\mathbb{D}}$, Jian Shi ${ }^{2}$, William A. Large ${ }^{3}$ and Anthony P. Albert ${ }^{3, * \mathbb{D}}$ \\ 1 Department of Pharmacology, University of California, Davis, CA 95615, USA; martinaragon@ucdavis.edu \\ 2 LIGHT Laboratories, Leeds Institute of Cardiovascular and Metabolic Medicine, University of Leeds, \\ Leeds LS2 9JT, UK; J.Shi1@leeds.ac.uk \\ 3 Vascular Biology Research Centre, Molecular and Clinical Research Institute, St. George's, \\ University of London, London SW17 0RE, UK; largew@sgul.ac.uk \\ * Correspondence: aalbert@sgul.ac.uk
}

Received: 25 November 2019; Accepted: 5 January 2020; Published: 10 January 2020

check for updates

\begin{abstract}
In vascular smooth muscle cells (VMSCs), the stimulation of store-operated channels (SOCs) mediate $\mathrm{Ca}^{2+}$ influx pathways which regulate important cellular functions including contraction, proliferation, migration, and growth that are associated with the development of vascular diseases. It is therefore important that we understand the biophysical, molecular composition, activation pathways, and physiological significance of SOCs in VSMCs as these maybe future therapeutic targets for conditions such as hypertension and atherosclerosis. Archetypal SOCs called calcium release-activated channels (CRACs) are composed of Orai1 proteins and are stimulated by the endo/sarcoplasmic reticulum $\mathrm{Ca}^{2+}$ sensor stromal interaction molecule 1 (STIM1) following store depletion. In contrast, this review focuses on proposals that canonical transient receptor potential (TRPC) channels composed of a heteromeric TRPC1/C5 molecular template, with TRPC1 conferring activation by store depletion, mediate SOCs in native contractile VSMCs. In particular, it summarizes our recent findings which describe a novel activation pathway of these TRPC1-based SOCs, in which protein kinase C (PKC)-dependent TRPC1 phosphorylation and phosphatidylinositol 4,5-bisphosphate $\left(\mathrm{PIP}_{2}\right)$ are obligatory for channel opening. This $\mathrm{PKC}$ - and $\mathrm{PIP}_{2}$-mediated gating mechanism is regulated by the $\mathrm{PIP}_{2}$-binding protein myristoylated alanine-rich $\mathrm{C}$ kinase (MARCKS) and is coupled to store depletion by TRPC1-STIM1 interactions which induce Gq/PLC $\beta 1$ activity. Interestingly, the biophysical properties and activation mechanisms of TRPC1-based SOCs in native contractile VSMCs are unlikely to involve Orai1.
\end{abstract}

Keywords: TRPC1; PKC; PIP 2 ; Gq; PLC; MARCKS; STIM1; Orai1; store-operated channels; vascular smooth muscle

\section{Introduction}

In vascular smooth muscle cells (VSMCs), neurotransmitters and hormones such as noradrenaline, adrenaline, angiotensin II (Ang II), and endothelin 1 (ET-1) produce an increase in cytosolic $\mathrm{Ca}^{2+}$ concentration $\left(\mathrm{Ca}^{2+}{ }_{\mathrm{i}}\right)$ (see [1-7] for reviews on $\mathrm{Ca}^{2+}$ signaling mechanisms in smooth muscle). This rise in $\mathrm{Ca}^{2+}{ }_{\mathrm{i}}$ is important for initiating vasoconstriction, which determines vascular resistance and blood pressure and ultimately regulates blood flow to our tissues and organs. In addition, an excessive increase in $\mathrm{Ca}^{2+}{ }_{\mathrm{i}}$ is linked to cell proliferation, migration and growth, phenotypes which are involved in the development of vascular disease. Therefore, understanding cellular pathways which mediate increases in $\mathrm{Ca}^{2+}{ }_{\mathrm{i}}$ may help to identify future therapeutic targets for conditions such as hypertension and atherosclerosis. 
Vasoconstrictors induce a rise in $\mathrm{Ca}^{2+}{ }_{\mathrm{i}}$ by activating the classical phosphoinositol signaling pathway involving: stimulation of Gq-protein-coupled receptors, phospholipase C (PLC) activity, phosphatidylinositol 4,5-bisphosphate $\left(\mathrm{PIP}_{2}\right)$ hydrolysis, and inositol 1,4,5-trisphosphate $\left(\mathrm{IP}_{3}\right)$ and diacylglycerol (DAG) generation [1-7]. $\mathrm{IP}_{3}$ mediates an increase in $\mathrm{Ca}^{2+}{ }_{\mathrm{i}}$ by causing the release of $\mathrm{Ca}^{2+}$ from sarcoplasmic reticulum (SR) $\mathrm{Ca}^{2+}$ stores, and this subsequent rise in $\mathrm{Ca}^{2+}{ }_{\mathrm{i}}$ and DAG-mediated pathways induce $\mathrm{Ca}^{2+}$ influx from the extracellular medium. A component of this $\mathrm{Ca}^{2+}$ influx occurs through activation of voltage-gated $\mathrm{Ca}^{2+}$ channels (VGCCs), but there is also a significant contribution from voltage-independent $\mathrm{Ca}^{2+}$-permeable non-selective cation channels. Stimulation of $\mathrm{Ca}^{2+}$-permeable cation channels are thought to mediate $\mathrm{Ca}^{2+}$ entry pathways through direct $\mathrm{Ca}^{2+}$ influx, and through $\mathrm{Na}^{+}$influx which leads to depolarization and activation of voltage-gated $\mathrm{Ca}^{2+}$ channels and stimulation of the $\mathrm{Na}^{+} / \mathrm{Ca}^{2+}$ exchanger in reverse mode.

There is substantial evidence that $\mathrm{Ca}^{2+}$-permeable non-selective cation channels classified as receptor-operated (ROCs) and store-operated (SOCs) are expressed in VSMCs [1,2]. ROCs are defined as ion channels activated by receptor stimulation independently of $\mathrm{IP}_{3}$-mediated depletion of SR $\mathrm{Ca}^{2+}$ stores, whereas SOCs are activated by pathways coupled to depletion of SR $\mathrm{Ca}^{2+}$ stores but not by the subsequent increase in $\mathrm{Ca}^{2+}{ }_{i}$. These definitions infer that stimulation of Gq-protein-coupled receptors will activate both ROCs and SOCs. In addition, it is proposed that SOCs may be activated by Gq-protein-coupled receptor stimulation independently of store depletion, hence SOCs may also function as ROCs [8]. Together, these findings make it difficult to study ROCs and SOCs independently of each other using macroscopic measurements such as whole-cell patch clamp and $\mathrm{Ca}^{2+}$ signal recordings but possible using single channel recordings [9-11]. Moreover, SOCs can be selectively activated by depleting SR $\mathrm{Ca}^{2+}$ stores in the absence of receptor stimulation using SR $\mathrm{Ca}^{2+}$-ATPase inhibitors (e.g., cyclopiazonic acid (CPA) and thapsigargin), and high (e.g., 1,2-bis(o-aminophyoxy)ethane- $N, N, N^{\prime}, N^{\prime}$-tetraacetic acid (BAPTA)) and low affinity (e.g., $N, N, N^{\prime}, N^{\prime}$,-tetrakis(2-pyridmethyl)-1,2-ethnediamine (TPEN)) $\mathrm{Ca}^{2+}$ chelators to passively deplete $\mathrm{Ca}^{2+}{ }_{\mathrm{i}}$ and $\mathrm{SR} \mathrm{Ca}^{2+}$ levels respectively.

This article reviews our current understanding of the biophysical properties, molecular composition, and activation mechanisms of SOCs in VSMCs, in particular, it focuses on recent studies from our laboratory which have described a novel activation pathway of SOCs composed of canonical transient receptor potential 1 (TRPC1) proteins in native contractile VSMCs. In the majority of these studies SOCs were activated by SR Ca ${ }^{2+}$ ATPase inhibitors or $\mathrm{Ca}^{2+}$ chelators to prevent complications from activation of ROCs, although in the final section we discuss the potential physiological significance of this store-operated activation pathway in vasoconstrictor-induced TRPC1-based SOCs.

\section{Biophysical Properties and Molecular Composition of SOCs in VSMCs}

It is well-established that archetypal SOCs, termed calcium release-activated channels (CRACs), are characterized by high $\mathrm{Ca}^{2+}$ permeabilities $\left(\mathrm{PCa}^{2+}: \mathrm{PNa}^{+}>1000: 1\right)$, pronounced inward rectification with reversal potentials $\left(\mathrm{E}_{\mathrm{rev}}\right)$ greater than $+50 \mathrm{mV}$, unitary conductances in the $\mathrm{fS}$ range, and are composed of Orai1 proteins (see [12] for review on properties and functions of Orai channels and their associated activation mechanisms). The fundamental activation mechanism of Orai1-based CRACs is also clearly outlined, with an essential role for stromal interaction molecule 1 (STIM1) which senses $\mathrm{Ca}^{2+}$ levels within ER/SR $\mathrm{Ca}^{2+}$ stores and following store depletion undergoes oligmerisation and translocation to cytosolic surface of the plasma membrane where it interacts with Orai1 to induce channel assembly and gating.

However, it is apparent that many cell types express SOCs with very different characteristics to Orai1-based CRACs such as much lower $\mathrm{Ca}^{2+}$ permeabilities, relatively linear or outward rectification, and considerably larger unitary conductances (see [13] for review on role of TRPC proteins in mediated SOCs). Given the properties of these SOCs, they are unlikely to be composed of Orai proteins. The molecular composition of these SOCs is controversial but there is increasing evidence that they are formed by the TRPC family of $\mathrm{Ca}^{2+}$-permeable non-selective cation channels (TRPC1-C7) [13]. These 
TRPC-based SOCs are likely to form a diverse group of channels with differing expression, properties, and functions since TRPC subunits form heterotetrameric structures $[7,13]$. There is further controversy over whether TRPC proteins form SOCs due to limited understanding, unlike with Orai proteins, of how store depletion couples to channel activation that is an essential requirement when defining SOCs. These issues are beginning to be unraveled by findings which suggest that store depletion activates TRPC-based SOCs through diverse STIM1-mediated processes including direct interactions between TRPC and Orai1 proteins, activation of Orai1-based CRACs as a prerequisite for TRPC1 opening, and direct interactions between TRPC and STIM1 $[13,14]$. For example, in overexpression studies it is proposed that direct interactions between STIM1 and TRPC channels govern activation [13-18], whereas elegant studies in salivary glands have shown that activation of TRPC1-based SOCs require prior activation of Orai1-based CRACs to induce insertion of TRPC1 subunits into the plasma membrane, with both activation of Orai1-based CRACs and TRPC1-based SOCs coupled to store depletion by STIM1 (see [19] for review on activation mechanisms of TRPC1-based SOCs in salivary glands). The studies highlighted in this review indicate that activation of STIM1-mediated TRPC1-based SOCs in native contractile VSMCs involves a Gq/PLC $\beta 1$ pathway and interactions between protein kinase C (PKC) activity and $\mathrm{PIP}_{2}$ which do not require Orai1.

The molecular composition and activation mechanisms of SOCs in VSMCs reflects the controversies highlighted above as there is significant evidence to indicate that both Orai1-based CRACs and TRPC-based SOCs are present in VSMCs, but that these channels are differentially expressed according to cell phenotype. In freshly isolated VSMCs or primary cultured VSMCs maintained in low serum, conditions in which VSMCs retain their native contractile phenotype, evidence suggests that SOCs have biophysical properties which resemble TRPC-based SOCs and not Orail-based CRACs with relatively linear, S-shaped, or slightly outward rectification, low $\mathrm{Ca}^{2+}$ permeabilities $\left(\mathrm{PCa}^{2+}: \mathrm{PNa}^{+}\right.$of $\left.1-50\right)$, and unitary conductances of $2-3 \mathrm{pS}$ and $2-8 \mathrm{pS}$ in $1.5 \mathrm{mM}$ and $0 \mathrm{mM}$ external $\mathrm{Ca}^{2+}$ respectively [1,2,20-29]. Moreover, studies using an array of different techniques such as blocking anti-TRPC antibodies (e.g., T1E3), TRPC1 ${ }^{-/}$mice, molecular knockdown (e.g., siRNA), and pharmacology (e.g., the selective TRPC1/C4/C5 inhibitor Pico145) $[30,31]$ indicate that these SOCs are composed of a heteromeric TRPC1/C5 molecular template, which can also involve other TRPC subunits depending on the vascular bed $[7,20-29,32,33]$. As such, these studies show that TRPC1/C5-based SOCs are functionally expressed in pial arterioles and mesentery artery VSMCs, whereas TRPC1/C5/C6- and TRPC1/C5/C7-based SOCs are reported in coronary artery and portal vein VSMCs respectively. It is predicted that differences in the molecular compositions of these TRPC-based SOCs are reflected in the different properties of TRPC-based SOCs such as rectification, $\mathrm{Ca}^{2+}$ permeability and unitary conductance. For example, inclusion of TRPC6 within the TRPC1/C5 template produces biophysical properties which indicate a decreased $\mathrm{Ca}^{2+}$ permeability [22], whereas the presence of TRPC7 produces a facilitatory action of $\mathrm{IP}_{3}$ on TRPC1-based SOCs [22,34]. Studies using TRPC1 ${ }^{-/-}$VSMCs indicate that TRPC1 is essential for conferring activation by store depletion, and therefore these TRPC1/C5 channel templates are termed TRPC1-based SOCs [25]. These findings fit with the idea that TRPC1 subunits do not form a functional homotetrameric channel [13]. Several studies have indicated that Orai1 proteins are unlikely to be involved in composing SOCs in VSMCs with a native contractile phenotype, with low expression of Orai1 proteins present in these cells $([35,36]$ and see $[37,38]$ for review of Orai1 proteins in vascular smooth muscle) and biophysical properties of TRPC1-based SOCs and their STIM1-mediated activation mechanisms unaffected in freshly isolated and primary cultured VSMCs from Orai1 ${ }^{-/}$mice [29].

In contrast to native contractile VSMCs, long-term cultured VSMCs maintained in high serum, conditions that induce a non-contractile synthetic phenotype with proliferative, migrative and growth characteristics, express whole-cell SOCs and store-operated $\mathrm{Ca}^{2+}$ entry with similar properties to Orai1-based CRACs such as pronounced inward rectification, inhibition by a Orai1 selective inhibitor, and inhibition by knockdown of Orai1 and STIM1 protein levels but not by knockdown of TRPC1, TRPC4 or TRPC6 proteins [36-42]. In addition, store-operated whole-cell currents and $\mathrm{Ca}^{2+}$ entry are 
unaffected in cultured VSMCs maintained in high serum conditions from TRPC1 ${ }^{-/-}$mice [43] further suggesting the involvement of Orai1-based CRACs in these VSMCs. In contrast, TRPC1 has also been proposed to be involved in regulating SOCs present in synthetic VSMCs, perhaps by regulating Orai1-based CRACs, and it is suggested that increase in the expression and function of TRPC1 may be an important trigger in the development of the cellular switch from a contractile to synthetic phenotype $[37,38]$.

These complexities mean that when studying SOCs in VSMCs it is essential to clearly define cell phenotype of VSMCs. In this regard, when investigating SOCs in native contractile VSMCs it is advantageous to use freshly isolated cells whenever possible, and when required only use primary culture cells maintained in low serum conditions for as short a time as possible.

\section{Activation Mechanisms of TRPC1-Based SOCs in Native Contractile VSMCs}

The following sections discuss our recent findings that TRPC1-based SOCs in freshly isolated and primary cultured VSMCs with a native contractile phenotype exhibit a complex activation mechanism, in which interactions between PKC-dependent phosphorylation of TRPC1 and phosphatidylinositol 4,5-bisphosphate $\left(\mathrm{PIP}_{2}\right)$ regulated by myristoylated alanine-rich $\mathrm{C}$ kinase (MARCKS) are obligatory gating partners, with these mechanisms coupled to store depletion by a novel STIM1-mediated Gq-PLC $\beta 1$ pathway.

\subsection{PKC Activity and PIP 2 have Obligatory Roles in Activation of TRPC1-based SOCs}

There are several lines of evidence which indicate that PKC activity and $\mathrm{PIP}_{2}$ are important in activating TRPC1-based SOCs. The stimulation of whole-cell and single channel TRPC1-based SOCs is significantly reduced by PKC inhibitors and anti-PIP 2 antibodies $[22,25,44]$. In support of these results, PKC activators (diacylglycerol analogues, phorbol esters, PKC catalytic subunits) and exogenous application of diC8-PIP 2 (a water-soluble form of PIP 2 ) stimulate TRPC1-based SOCs in WT but not in TRPC1 ${ }^{-/-}$VSMCs $[22,25,44]$. Interestingly, PKC-stimulated activation of TRPC1-based SOCs are prevented by anti-PIP 2 antibodies and pharmacological agents such as wortmannin to deplete $\mathrm{PIP}_{2}$ levels, whereas diC8-PIP ${ }_{2}$-activated TRPC1-based SOCs are reduced by PKC inhibitors [44]. Moreover, store depletion induces PKC-dependent phosphorylation of TRPC1 and increases association between $\mathrm{PIP}_{2}$ and TRPC1 $[26-28,44]$. Together, these results indicate that interactions between PKC activity and PIP 2 have obligatory roles in activation of TRPC1-based SOCs; PKC cannot activate TRPC1-based SOCs without $\mathrm{PIP}_{2}$, and vice versa. This supports the hypothesis that $\mathrm{PIP}_{2}$ is the activating ligand of TRPC1-based SOCs and that store-operated PKC-dependent phosphorylation of TRPC1 is required for this opening mechanism to occur.

These proposed roles of PKC and PIP 2 on TRPC1-based SOCs are different to their roles in the activation of TRPC3/C6/C7-based ROCs in native contractile VSMCs (see $[23,24]$ for comprehensive reviews of activation mechanisms of TRPC channels). It is well established that this subgroup of TRPC channels are activated by receptor-mediated generation of DAG which leads to channel opening via PKC-independent mechanisms, with PKC causing channel inhibition. In addition, the role of PIP 2 on TRPC3/C6/C7-based ROCs is unclear with both inhibitory and excitatory actions proposed [45,46]. These findings further indicate that TRPC1-based SOCs and TRPC3/C6/C7-based ROCs form distinct channel structures with differing activation mechanisms, and likely distinct functions in VSMCs.

Important omissions from our understanding are what PKC isoform(s) is involved, which amino acid(s) within TRPC1 protein structure is phosphorylated, and how a PKC-dependent phosphorylation process alters interactions between TRPC 1 and $\mathrm{PIP}_{2}$. The PKC family comprises of at least 11 serine/threonine kinases divided into three groups according to their basic structure and activation requirements: conventional PKC isoforms $(\alpha, \beta \mathrm{I}, \beta \mathrm{II}$ and $\gamma)$ require both $\mathrm{Ca}^{2+}$ and diacylglycerol (DAG), novel PKC isoforms $\left(\delta, \varepsilon, \eta\right.$ and $\theta$ ) require DAG but are $\mathrm{Ca}^{2+}$-insensitive, and atypical PKC isoforms $(\zeta, \iota$ and $\lambda)$ are activated by lipid mediators such as phosphatidylserine and do not require $\mathrm{Ca}^{2+}$ or DAG (see [47] for review of the role of PKC isoforms in vascular smooth muscle). Our results 
indicate that stimulation of TRPC1-based SOCs and PKC-dependent phosphorylation of TRPC1 by store depletion requires PLC $\beta 1$ activity, and that DAG analogues activate TRPC1-based SOCs through a PKC-dependent mechanism [9,23,24,27]. Moreover, we have shown that TRPC1-based SOCs are activated by store depleting agents which are likely to increase (e.g., CPA), decrease (e.g., the high affinity cell-impermeable and -permeable $\mathrm{Ca}^{2+}$ chelators BAPTA and BAPTA-AM), or produce little change in $\mathrm{Ca}^{2+}{ }_{\mathrm{i}}$ (e.g., the low affinity cell-permeable $\mathrm{Ca}^{2+}$ chelator TPEN). These findings suggest that the PKC isoform involved is likely to require DAG but is $\mathrm{Ca}^{2+}$-insensitive, which are characteristics of the novel group of PKC isoforms. Our preliminary data indicate that PKC $\delta$ is the most highly expressed novel PKC isoform in VSMCs, and that selective PKC $\delta$ inhibitory peptides and knockdown of PKC $\delta$ using morpholino sequences prevent activation of TRPC1-based SOCs [31].

Interestingly, the predication of PKC $\delta$-dependent phosphorylation sites within the TRPC1 sequence using GPS 3.0 reveals five intracellular serine residues, with Ser619 and Ser752 at the C-terminal domain of potential significance as both these sites are close to a known $\mathrm{PIP}_{2}$-binding domain [48]. It is therefore possible that PKC $\delta$-dependent phosphorylation of these sites increases $\mathrm{PIP}_{2}$ affinity leading to increased binding to TRPC1 and channel opening. Previous studies have highlighted that protein kinase A (PKA), protein kinase G (PKG), and calmodulin kinase II (CaMKII) have inhibitory actions on TRPC1-based SOCs in VSMCs [49-51], and it may be that phosphorylation of serine/threonine amino acids by these kinases reduce TRPC1 and $\mathrm{PIP}_{2}$ interactions by lowering $\mathrm{PIP}_{2}$ affinity. Similar roles for kinase activities in modulating lipid-protein interactions are well-established in the regulation of different $\mathrm{K}^{+}$channel subtypes [52].

\subsection{Interactions Between PKC Activity and $\mathrm{PIP}_{2}$ are Regulated by MARCKS}

An important question is how PKC-dependent phosphorylation regulates $\mathrm{PIP}_{2}$ gating of TRPC1-based SOCs when physiological activators of SOCs involve stimulation of Gq-coupled receptors which drive PLC activity and $\mathrm{PIP}_{2}$ hydrolysis. To provide answers to this question, we investigated the role of MARCKS in activation of TRPC1-based SOCs. MARCKS is a membrane-bound PIP $_{2}$-binding protein that acts a $\mathrm{PIP}_{2}$ buffer, which can provide a distinct pool of $\mathrm{PIP}_{2}$ at the plasma membrane that is protected from breakdown by PLC thus enabling this phospholipid to be released in a coordinated manner into the local environment $[53,54]$. Using a combination of electrophysiological, co-immunoprecipitation, and $\mathrm{PIP}_{2}$-binding dot-blot assays, we showed that in unstimulated conditions MARCKS is bound to TRPC1, with PIP 2 predominately associated with MARCKS and not TRPC1 [26]. Upon stimulation by store depleting agents MARCKS dissociates from TRPC1, which leads to PIP 2 being released and associated with TRPC1 to cause channel opening. Importantly, both dissociation of MARCKS from TRPC1 and redistribution of PIP 2 from MARCKS to TRPC1 are stimulated by phorbol esters and prevented by PKC inhibitors indicating that PKC activity is central to these mechanisms. It will be important to ascertain how receptor stimulation and store-depleting agents couple to these actions of MARCKS. A potential idea is that stimulation of CaM is involved, as this $\mathrm{Ca}^{2+}$-binding protein is known to bind to MARCKS and to cause dissociation from the plasma membrane and $\mathrm{PIP}_{2}$ release [53,55]. Furthermore, CaM is known to activate TRPC1-based SOCs in native contractile VSMCs [50].

\subsection{Store Depletion Activates a Gq-PLC $\beta 1$ Pathway Involved in Activation of TRPC1-Based SOCs}

For a channel to be defined as store-operated, it is essential to understand how store depletion is coupled to channel opening. Therefore, a central question surrounding the activation of TRPC1-based SOCs is how store depletion couples to PKC-dependent phosphorylation of TRPC1 and opening by PIP 2 ? A crucial finding was the discovery that store depletion activates a Gq-PLC $\beta 1$ pathway which drives the PKC-dependent phosphorylation of TRPC1 [27]. Our studies showed that the G-protein inhibitor GDP- $\beta-S$, anti-Gq antibodies (but not anti-Gi), the PLC inhibitor U73122, and PLC $\beta 1$ shRNA inhibited activation of TRPC1-based SOCs. In addition, store-operated PKC-dependent phosphorylation of TRPC1 was inhibited by U73122 and PLC $\beta 1$ shRNA. A significant finding was that store depleting 
agents induced PLC activity measured using GFP-PLC 81 -PH, a fluorescent biosensor for $\mathrm{PIP}_{2}$ and $\mathrm{IP}_{3}$ ([56-58] and reviewed in [59]) in primary cultured VSMCs which was prevented by a PLC inhibitor and PLC $\beta 1$ shRNA. In support of these findings, co-immunoprecipitation and proximity ligation assays (PLA) demonstrated that store depletion induced interactions between TRPC1, Gq and PLC $\beta 1$ at the plasma membrane.

\subsection{STIM1 Couples Store Depletion to Gq-PLC $\beta 1$ Activity to Stimulate TRPC1 SOCs}

Next, we investigated how store depletion is coupled to the formation and activation of this Gq/PLC $\beta 1 / P K C / T R P C 1$ signal transduction pathway. An obvious candidate was STIM1, since along with its classically described role in activating Orai1-based CRACs it has been implicated in activating TRPC-based SOCs (see [13] for review). Moreover, it is known that that STIM1 has diverse cellular partners including ion channels [12,13,15-18,60,61], SR and plasma membrane ATPases [62,63], and adenylate cyclase [64] and therefore it seemed a reasonable idea that STIM1 may couple to Gq/PLC $\beta 1$ activity.

We demonstrated that whole-cell and single channel TRPC1-based SOCs and store-operated PLC $\beta 1$ activity were inhibited by shRNA STIM1 and were absent in TRPC1 ${ }^{-/-}$VSMCs [28]. In addition, store-operated PKC-dependent phosphorylation of TRPC1 was greatly reduced by shRNA STIM1. Moreover, STIM1 was required for store-operated interactions between Gq, PLC $\beta 1$ and TRPC1, and TRPC1 was essential for store-operated interactions between Gq, PLC $\beta 1$, and STIM1. These findings provide strong evidence that STIM1 is an essential molecule in activation of TRPC1-based SOCs, and importantly it indicates that store-operated STIM1-TRPC1 interactions (measured using PLA assays which imply that these interactions occur within $40 \mathrm{~nm}$ ) form the structural basis for stimulation of the Gq/PLC $\beta 1$ pathway required for PKC-dependent TRPC1 phosphorylation and channel opening by $\mathrm{PIP}_{2}$.

As expected, store depletion induced translocation of STIM1 from the cytosol to the plasma membrane where it formed discrete puncta and interactions with TRPC1 using immunocytochemical and PLA techniques, which were not dependent on downstream molecules in the signal pathway such as PLC $\beta 1$ [28]. Interestingly, in the absence of TRPC1, store depletion still induced translocation of STIM1 from cytosol to the plasma membrane, but STIM1 formed an even distribution throughout the plasma membrane and not discrete puncta. This suggests that TRPC1 may be essential for coordinating the response of STIM1 to store depletion.

An interpretation from these studies is that STIM1-TRPC1 interactions, possibly involving other unknown molecules, act as a cellular activator of $\mathrm{Gq}$ subunits, and that this leads to interactions with, and activation of, PLC $\beta 1$. In essence STIM1-TRPC1 interactions behave like Gq-coupled receptors or guanine exchange factors (GEFs). In the future, it will be important to investigate structural interactions between STIM1 and TRPC1 and discover where Gq subunits binds. Initial work might focus on the CRAC-activating (CAD) and polybasic domains which have been linked to binding and activation of TRPC1 by protein-protein interactions and electrostatic interactions respectively [13,15-18].

Interestingly, differential blocking effects of N-terminal and C-terminal anti-STIM1 antibodies on TRPC1-based SOCs using whole-cell and inside-out patch clamp recordings may suggest that store-operated STIM1/TRPC1 interactions lead to STIM1 acting as a transmembrane protein at the plasma membrane [28]. In this configuration, the N-terminal domain of STIM1 is now present at the extracellular surface of the plasma membrane. Perhaps this orientation of STIM1-TRPC1 interactions has implications for association with Gq subunits in native contractile VSMCs. A similar role for STIM1 has been previously described in mediating store-operated conductances [65]. However, it seems unlikely that the source of STIM1 involved in activating TRPC1-based SOCs resides at the plasma membrane, as with activation of arachidonic acid-regulated channels (ARC) composed of Orai1/Orai3 subunits [66], since our data indicates that store depletion induces translocation of STIM1 from the cytosol to the plasma membrane. 


\subsection{Activation Mechanisms of TRPC1-Based SOCs are Independent of Orai1}

There is substantial evidence that TRPC1, Orai1 and STIM1 have important roles in mediating store-operated $\mathrm{Ca}^{2+}$ entry pathways in VSMCs with a synthetic phenotype, although it is unclear whether Orai1 and TRPC1 interact together or form separate STIM1-mediated ionic mechanisms (see earlier). In addition, it is unclear whether Orai1 is required for activation of TRPC1-based SOCs in native contractile VSMCs. In our recent study, we showed that the properties of store-operated whole-cell and single channel currents in freshly isolated and primary cultured native contractile WT and Orai1 ${ }^{-/-}$VSMCs were similar to previously described TRPC1-based SOCs, and that store-operated STIM1-mediated PLC $\beta 1$ activity and STIM1-TRPC1 interactions were unaffected in Orai1 ${ }^{-/-}$cells [29]. These findings provide significant evidence that Orai1 proteins are not required for the molecular composition or activation mechanisms of TRPC1-based SOCs in contractile VSMCs. These results support the findings that Orai1 expression is very low in native contractile VSMCs [35-38]. A caveat is that Orai proteins are composed of three subtypes, Orai1-3 [12], and therefore Orai2 and Orai3 may be involved in TRPC1-based SOCs in native contractile VSMCs. However, whole-cell store-operated conductances with the distinct characteristics of Orai proteins, such as such inward rectification, and reversal potential greater than $+50 \mathrm{mV}$ have not been identified in native contractile VSMCs from WT, Orai $1^{-/-}$or TRPC $1^{-/-}$preparations $[25,29]$.

It should be noted that other studies using pharmacological and molecular techniques have implicated Orai1 and $\mathrm{Ca}^{2+}$-independent phospholipase $\mathrm{A}_{2}\left(\mathrm{iPLA}_{2}\right)$ in store-operated conductances in native and primary cultured contractile VSMCs [67]. These studies propose that store depletion linked to STIM1-mediated release of a calcium influx factor (CIF) from the SR activates Orai1 through an iPLA ${ }_{2}$-mediated mechanism involving production of lysophospholipids (see [68] for review). In addition, Orai1 has been proposed alongside TRPC1 to regulate store-operated vascular contractility through interactions with voltage-gated $\mathrm{Ca}^{2+}$ channels ([69] and reviewed in [70]). The differences between these findings to those described above are unclear and may reflect differences between SOCs in different vascular beds and perhaps different cell isolation or culturing conditions. However, before these ideas can be truly accepted it will be essential to resolve the identity of CIF and understand why proposed Orai1-sensitive currents in contractile VSMCs have such a linear rectification [67]. For example, do contractile VSMCs express an Orai1 splice variant with very different properties to established Orai-based CRACs? In addition, a difficult finding to explain is why store-operated conductances are absent in native contractile VSMCs from TRPC1 ${ }^{-1-}$ mice [25]. Moreover, involvement of iPLA ${ }_{2}$ has been inferred in many studies using the proposed inhibitor bromoenol lactone (BEL), which has also been shown to block heteromeric TRPC1/C5, TRPC5, and TRPC6 channels and VGCCs [71].

\section{Physiological Significance of TRPC1-Based SOCs Activation Pathway}

To avoid complications from receptor-operated pathways, most studies use agents that selectively deplete SR $\mathrm{Ca}^{2+}$ stores (e.g., CPA, BAPTA) instead of receptor stimulation to study SOCs (see Introduction). However, it is important to examine whether proposed store-operated mechanisms are involved in activation of SOCs by physiological receptor stimulation. This is particularly important for TRPC1-based SOCs in native contractile VSMCs as these channels also behave as ROCs, and so may be activated by distinct store-independent and -dependent pathways [1,2]. Previous studies have shown that noradrenaline, Ang II and ET-1-activated $\mathrm{ET}_{\mathrm{B}}$ receptor stimulation induce TRPC1-based SOCs via a PLC-mediated pathway that requires PKC activity and $\mathrm{PIP}_{2}$ for channel opening in portal vein, mesenteric artery and coronary artery VSMCs respectively [8-11,23,72]. To investigate whether these receptor-mediated activation pathways of TRPC1-based SOCs might involve our proposed store-operated STIM1/Gq/PLC $\beta 1$ pathway, we showed that noradrenaline-activated TRPC1-based SOCs were greatly reduced by knockdown of PLC $\beta 1$ and STIM1 and that noradrenaline also induced interactions between STIM1 and TRPC1, Gq, and PLC $\beta 1[27,28]$. Moreover, noradrenaline induced PKC-dependent phosphorylation of TRPC1 and activation of TRPC1-based SOCs by regulating MARCKS-TRPC1-PIP 2 interactions similar to those produced by store depleting agents [26]. These 
findings highlight that physiological receptor stimulation is likely to activate TRPC1-based SOCs through the store-operated STIM1/Gq/PLC $\beta 1 / \mathrm{PKC}$ pathway and also via a store-independent pathway involving a Gq/PLC/PKC pathway. It may be that receptor stimulation switches between these two modes to activate TRPC1-based SOCs according to concentration of the physiological agonist. For example, higher vasoconstrictor concentrations may be more likely to produce substantial $\mathrm{IP}_{3}$-mediated depletion of SR Ca ${ }^{2+}$ stores and activation of TRPC1-based SOCs by store depletion.

It is likely that certain receptors only activate TRPC1-based SOCs via store-independent pathways. In native contractile coronary artery VSMCs, ET-1-activated $\mathrm{ET}_{\mathrm{A}}$ receptor stimulation induces TRPC1-based SOCs through a G $\beta \gamma$-protein-phosphoinositol 3-kinase (PI3K)-mediated pathway, with $\mathrm{PIP}_{3}$ formation thought to both induce PKC activity and act as the channel activating ligand; a pathway which is unlikely to involve $\mathrm{IP}_{3}$-mediated depletion of $\mathrm{SR} \mathrm{Ca}^{2+}$ stores [11,72]. Therefore, TRPC1-based SOCs in coronary artery VSMCs are activated by $\mathrm{ET}_{\mathrm{A}}$ and $\mathrm{ET}_{\mathrm{B}}$ receptor stimulation through separate store-independent and -dependent pathways respectively, both requiring obligatory roles of PKC activity and phospholipids $[11,66]$.

Interestingly, the knockdown of PLC $\beta 1$ and STIM1 had little effect on noradrenaline-stimulated PLC activity measured using the GFP-PLC $\delta$-PH biosensor, although it was inhibited by U73122 a general PLC isoform inhibitor $[27,28]$. These findings support significant physiological relevance to our results, as it suggests that stimulation of Gq-protein-coupled receptors and $\mathrm{IP}_{3}$-mediated depletion of $\mathrm{SR} \mathrm{Ca}^{2+}$ stores are likely to activate two different Gq-PLC pathways mediated by distinct PLC isoforms. To test this hypothesis, it would be important to identify the PLC isoform linked to $\alpha_{1}$-adrenoceptor stimulation. The critical role of MARCKS in stimulation of TRPC1-based SOCs is further highlighted when considering the physiological significance of our proposed activation pathway. Stimulation of Gq-protein-coupled receptors and $\mathrm{IP}_{3}$-mediated depletion of $\mathrm{SR} \mathrm{Ca}^{2+}$ stores will both induce Gq-PLC activities leading to $\mathrm{PIP}_{2}$ hydrolysis. Therefore, MARCKS provides the essential role of a buffering a separate pool of PIP 2 , which is protected from PLC-mediated hydrolysis enabling the phospholipid to be available for channel opening.

\section{Summary}

This review highlights recent findings that SOCs in native contractile VSMCs are mediated by TRPC1-based SOCs, which have very different biophysical properties to the well-characterized channels formed by Orai proteins, including archetypal Orai1-based CRACs. Moreover, Figure 1 describes a novel activation pathway for these TRPC1-based SOCs proposed from our recent studies, in which $\mathrm{SR} \mathrm{Ca}{ }^{2+}$ store depletion by receptor-induced $\mathrm{IP}_{3}$-mediated generation or store depleting agents such as CPA and BAPTA stimulate STIM1 to translocate to the plasma membrane where it interacts with TRPC1 subunits to form a receptor for Gq G-protein subunits which induces PLC $\beta 1$ activity, production of DAG, and PKC activity. PKC-dependent phosphorylation of TRPC1 increases PIP 2 binding and channel opening. The interactions between TRPC1 and PIP 2 are regulated by MARCKS, a plasma membrane $\mathrm{PIP}_{2}$-binding protein bound to TRPC1 at rest, which upon store depletion dissociates from TRPC1 and releases PIP 2 into the local environment where the phospholipid acts as the gating ligand. Figure 1 also depicts our current understanding of how receptor stimulation by vasoconstrictors activates TRPC1-based SOCs in contractile VSMCs by store-independent pathways involving PKC activity and phospholipids. 


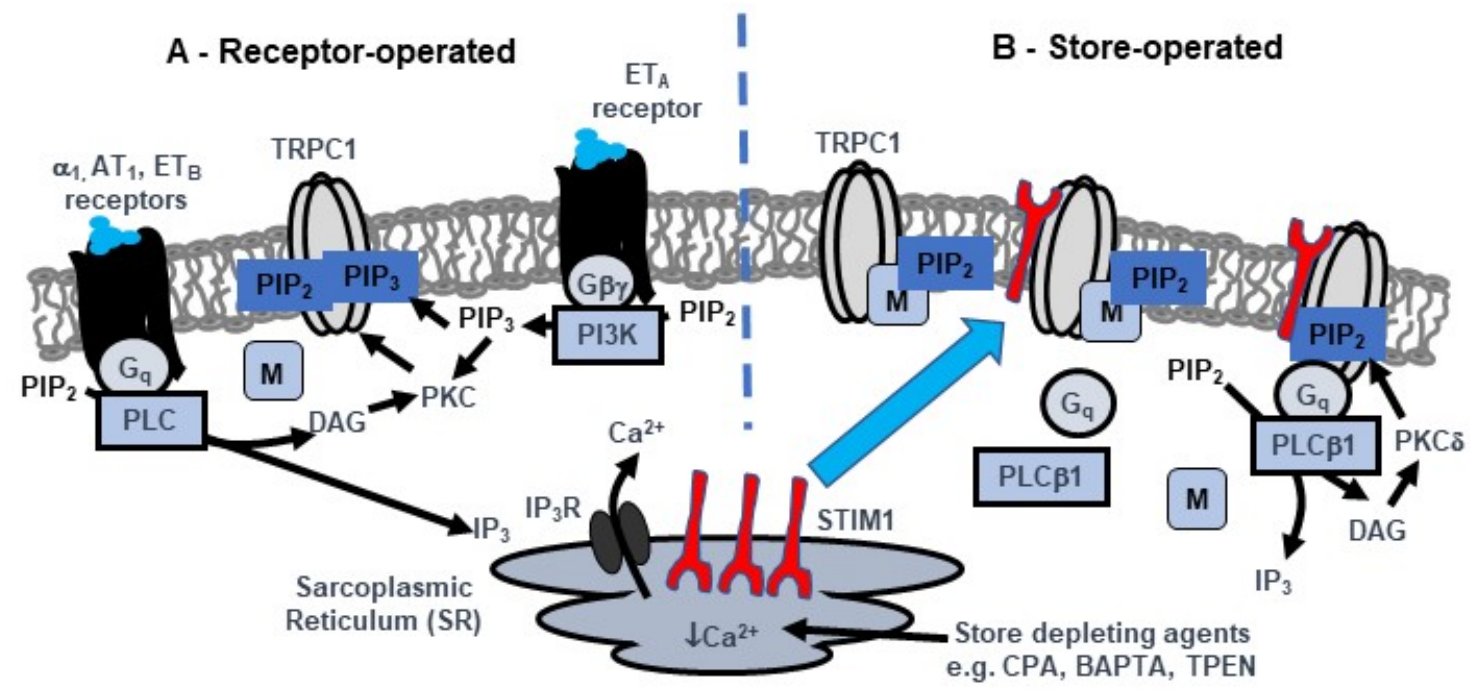

Figure 1. Proposed model of TRPC1-based store-operated channels (SOCs) in native contractile vascular smooth muscle cells (VSMCs). A, Receptor stimulation of distinct Gq-PLC and G $\beta \gamma-\mathrm{PI} 3 \mathrm{~K}-\mathrm{PIP}{ }_{3}$ pathways lead to PKC-dependent phosphorylation of TRPC1 and channel opening by $\mathrm{PIP}_{2}$ and $\mathrm{PIP}_{3}$ respectively. Local levels of $\mathrm{PIP}_{2}$ involved in channel activation is controlled by MARCKS (M). B, Store depletion by receptor-mediated $\mathrm{IP}_{3}$ generation and store depleting agents such as CPA, BAPTA and TPEN activate TRPC1-based SOCs through a STIM1-TRPC1-mediated pathway. In unstimulated cells, SR Ca ${ }^{2+}$ stores are full and TRPC1-based SOCs are in a closed state. In this configuration, channels are associated with MARCKS which buffers local PIP 2 levels and do not interact with Gq, PLC $\beta 1$ or STIM1. Following SR Ca ${ }^{2+}$ depletion, STIM1 (red) is activated and translocates from the SR to the plasma membrane where it interacts with TRPC1. Formation of STIM1-TRPC1 interactions enable binding and activation of Gq and PLC $\beta 1$ activity, $\mathrm{PIP}_{2}$ hydrolysis, DAG generation, stimulation PKC $\delta$ and PKC-dependent phosphorylation of TRPC1. This leads to dissociation of MARCKS from TRPC1 and release of $\mathrm{PIP}_{2}$ (previously protected from $\mathrm{PIP}_{2}$ hydrolysis) into the local environment where it acts as the activating ligand.

Author Contributions: All authors were involved in production of this manuscript and have discussed the final version of the manuscript.

Funding: This work was supported by Biotechnology and Biological Sciences Research Council grants (BB/J007226/1 and BB/M018350/1 to APA).

Conflicts of Interest: To the best of our knowledge, the authors declare no conflict of interest.

\section{References}

1. Albert, A.P.; Large, W.A. Store-operated $\mathrm{Ca}^{2+}$-permeable non-selective cation channels in smooth muscle cells. Cell Calcium 2003, 33, 345-356. [CrossRef]

2. Albert, A.P.; Saleh, S.N.; Peppiatt-Wildman, C.M.; Large, W.A. Multiple activation mechanisms of store-operated TRPC channels in smooth muscle cells. J. Physiol. 2007, 583, 25-36. [CrossRef] [PubMed]

3. Abramowitz, J.; Birnbaumer, L. Physiology and pathophysiology of canonical transient receptor potential channels. FASEB J. 2009, 23, 297-328. [CrossRef] [PubMed]

4. Beech, D.J. Characteristics of transient receptor potential canonical calcium-permeable channels and their relevance to vascular physiology and disease. Circ. J. 2013, 77, 570-579. [CrossRef]

5. Earley, S.; Brayden, J.E. Transient receptor potential channels in the vasculature. Physiol. Rev. 2015, 95, 645-690. [CrossRef]

6. Large, W.A. Receptor-operated $\mathrm{Ca}^{2+}$-permeable nonselective cation channels in vascular smooth muscle: A physiologic perspective. J. Cardiovasc. Electrophysiol. 2002, 13, 493-501. [CrossRef]

7. Albert, A.P.; Saleh, S.N.; Large, W.A. Identification of canonical transient receptor potential (TRPC) channel proteins in native vascular smooth muscle cells. Curr. Med. Chem. 2009, 16, 1158-1165. [CrossRef] 
8. Albert, A.P.; Large, W.A. Activation of store-operated channels by noradrenaline via protein kinase C in rabbit portal vein myocytes. J. Physiol. 2002, 544, 113-125. [CrossRef]

9. Saleh, S.N.; Albert, A.P.; Peppiatt, C.M.; Large, W.A. Angiotensin II activates two cation conductances with distinct TRPC1 and TRPC6 channel properties in rabbit mesenteric artery myocytes. J. Physiol. 2006, 577, 479-495. [CrossRef]

10. Shi, J.; Ju, M.; Saleh, S.N.; Albert, A.P.; Large, W.A. TRPC6 channels stimulated by angiotensin II are inhibited by TRPC1/C5 channel activity through a $\mathrm{Ca}^{2+}$ - and PKC-dependent mechanism in native vascular myocytes. J. Physiol. 2010, 588, 3671-3682. [CrossRef]

11. Shi, J.; Ju, M.; Large, W.A.; Albert, A.P. Pharmacological profile of phosphatidylinositol 3-kinases and related phosphatidylinositols mediating endothelin(A) receptor-operated native TRPC channels in rabbit coronary artery myocytes. Br. J. Pharmacol. 2012, 166, 2161-2175. [CrossRef]

12. Prakriya, M.; Lewis, R.S. Store-operated calcium channels. Physiol. Rev. 2015, 95, 1383-1436. [CrossRef]

13. Cheng, K.T.; Ong, H.L.; Liu, X.; Ambudkar, I.S. Contribution and regulation of TRPC channels in store-operated $\mathrm{Ca}^{2+}$ entry. Curr. Top. Membr. 2013, 71, 149-179.

14. Liao, Y.; Abramowitz, J.; Birnbaumer, L. The TRPC family of TRP channels: Roles inferred (mostly) from knockout mice and relationship to ORAI proteins. Handb. Exp. Pharmacol. 2014, 223, 1055-1075.

15. Worley, P.F.; Zeng, W.; Huang, G.N.; Yuan, J.P.; Kim, J.Y.; Lee, M.G.; Muallem, S. TRPC channels as STIM1-regulated store-operated channels. Cell Calcium 2007, 42, 205-211. [CrossRef]

16. Yuan, J.P.; Kim, M.S.; Zeng, W.; Shin, D.M.; Huang, G.; Worley, P.F.; Muallem, S. TRPC channels as STIM1-regulated SOCs. Channels 2009, 3, 221-225. [CrossRef]

17. Lee, K.P.; Choi, S.; Hong, J.H.; Ahuja, M.; Graham, S.; Ma, R.; So, I.; Shin, D.M.; Muallem, S.; Yuan, J.P. Molecular determinants mediating gating of transient receptor potential canonical (TRPC) channels by stromal interaction molecule 1 (STIM1). J. Biol. Chem. 2014, 289, 6372-6382. [CrossRef]

18. Asanov, A.; Sampieri, A.; Moreno, C.; Pacheco, J.; Salgado, A.; Sherry, R.; Vaca, L. Combined single channel and single molecule detection identifies subunit composition of STIM1-activated transient receptor potential canonical (TRPC) channels. Cell Calcium 2015, 57, 1-13. [CrossRef]

19. Ambudkar, I.S.; de Souza, L.B.; Ong, H.L. TRPC1, Orai1, and STIM1 in SOCE: Friends in tight spaces. Cell Calcium 2017, 63, 33-39. [CrossRef]

20. Trepakova, E.S.; Gericke, M.; Hirakawa, Y.; Weisbrod, R.M.; Cohen, R.A.; Bolotina, V.M. Properties of a native cation channel activated by $\mathrm{Ca}^{2+}$ store depletion in vascular smooth muscle cells. J. Biol. Chem. 2001, 276, 7782-7790. [CrossRef]

21. Albert, A.P.; Large, W.A. A $\mathrm{Ca}^{2+}$-permeable non-selective cation channel activated by depletion of internal $\mathrm{Ca}^{2+}$ stores in single rabbit portal vein myocytes. J. Physiol. 2002, 538,717-728. [CrossRef] [PubMed]

22. Saleh, S.N.; Albert, A.P.; Peppiatt-Wildman, C.M.; Large, W.A. Diverse properties of store-operated TRPC channels activated by protein kinase C in vascular myocytes. J. Physiol. 2008, 586, 2463-2476. [CrossRef]

23. Large, W.A.; Saleh, S.N.; Albert, A.P. Role of phosphoinositol 4,5-bisphosphate and diacylycerol in regulating native TRPC channel proteins in vascular smooth muscle. Cell Calcium 2009, 45, 574-582. [CrossRef]

24. Albert, A.P. Gating mechanisms of canonical transient receptor potential channel proteins: Role of phosphoinositols and diacylglycerol. Adv. Exp. Med. Biol. 2011, 704, 391-411.

25. Shi, J.; Ju, M.; Abramowitz, J.; Large, W.A.; Birnbaumer, L.; Albert, A.P. TRPC1 proteins confer PKC and phosphoinositol activation on native heteromeric TRPC1/C5 channels in vascular smooth muscle: Comparative study of wild-type and TRPC1-/- mice. FASEB J. 2012, 26, 409-419. [CrossRef]

26. Shi, J.; Birnbaumer, L.; Large, W.A.; Albert, A.P. Myristoylated alanine-rich C kinase substrate coordinates native TRPC1 channel activation by phosphatidylinositol 4,5-bisphosphate and protein kinase $\mathrm{C}$ in vascular smooth muscle. FASEB J. 2014, 28, 244-255. [CrossRef]

27. Shi, J.; Miralles, F.; Birnbaumer, L.; Large, W.A.; Albert, A.P. Store depletion induces G $\alpha q-$ mediated PLC $\beta 1$ activity to stimulate TRPC1 channels in vascular smooth muscle cells. FASEB J. 2016, 30, 702-715. [CrossRef]

28. Shi, J.; Miralles, F.; Birnbaumer, L.; Large, W.A.; Albert, A.P. Store-operated interactions between plasmalemmal STIM1 and TRPC1 proteins stimulate PLC $\beta 1$ to induce TRPC1 channel activation in vascular smooth muscle cells. J. Physiol. 2017, 595, 1039-1058. [CrossRef]

29. Shi, J.; Miralles, F.; Kinet, J.P.; Birnbaumer, L.; Large, W.A.; Albert, A.P. Evidence that Orai1 does not contribute to store-operated TRPC1 channels in vascular smooth muscle cells. Channels 2017, 11, 329-339. [CrossRef] 
30. Rubaiy, H.N.; Ludlow, M.J.; Henrot, M.; Gaunt, H.J.; Miteva, K.; Cheung, S.Y.; Tanahashi, Y.; Hamzah, N.; Musialowski, K.E.; Blythe, N.M.; et al. Picomolar, selective, and subtype-specific small-molecule inhibition of TRPC1/4/5 channels. J. Biol. Chem. 2017, 292, 8158-8173. [CrossRef]

31. Martin-Aragon Baudel, M.; Shi, J.; Jahan, K.S.; Large, W.A.; Albert, A.P. Obligatory role for PKC $\delta$ in PIP2-mediated activation of store-operated TRPC1 channels in vascular smooth muscle cells (manuscript in preparation). (manuscript in preparation).

32. Xu, S.Z.; Beech, D.J. TrpC1 is a membrane-spanning subunit of store-operated $\mathrm{Ca}^{2+}$ channels in native vascular smooth muscle cells. Circ. Res. 2001, 88, 84-87. [CrossRef] [PubMed]

33. Xu, S.Z.; Boulay, G.; Flemming, R.; Beech, D.J. E3-targeted anti-TRPC5 antibody inhibits store-operated calcium entry in freshly isolated pial arterioles. Am. J. Physiol. Heart Circ. Physiol. 2006, 291, H2653-H2659. [CrossRef]

34. Liu, M.; Albert, A.P.; Large, W.A. Facilitatory effect of $\operatorname{Ins}(1,4,5) \mathrm{P}_{3}$ on store-operated $\mathrm{Ca}^{2+}$-permeable cation channels in rabbit portal vein myocytes. J. Physiol. 2005, 566, 161-171. [CrossRef]

35. Berra-Romani, R.; Mazzocco-Spezzia, A.; Pulina, M.V.; Golovina, V.A. $\mathrm{Ca}^{2+}$ handling is altered when arterial myocytes progress from a contractile to a proliferative phenotype in culture. Am. J. Physiol. Cell Physiol. 2008, 295, C779-C790. [CrossRef]

36. Potier, M.; Gonzalez, J.C.; Motiani, R.K.; Abdullaev, I.F.; Bisaillon, J.M.; Singer, H.A.; Trebak, M. Evidence for STIM1- and Orai1-dependent store-operated calcium influx through ICRAC in vascular smooth muscle cells: Role in proliferation and migration. FASEB J. 2009, 23, 2425-2437. [CrossRef]

37. Beech, D.J. Orai1 calcium channels in the vasculature. Pflug. Arch. 2012, 463, 635-647. [CrossRef]

38. Trebak, M. STIM/Orai signalling complexes in vascular smooth muscle. J. Physiol. 2012, 590, 4201-4208. [CrossRef]

39. Li, J.; Sukumar, P.; Milligan, C.J.; Kumar, B.; Ma, Z.Y.; Munsch, C.M.; Jiang, L.H.; Porter, K.E.; Beech, D.J. Interactions, functions, and independence of plasma membrane STIM1 and TRPC1 in vascular smooth muscle cells. Circ. Res. 2008, 103, 97-104. [CrossRef]

40. Ng, L.C.; O'Neill, K.G.; French, D.; Airey, J.A.; Singer, C.A.; Tian, H.; Shen, X.M.; Hume, J.R. TRPC1 and STIM1 mediate capacitative $\mathrm{Ca}^{2+}$ entry in mouse pulmonary arterial smooth muscle cells. J. Physiol. 2009, 587, 2429-2442. [CrossRef]

41. Ng, L.C.; Ramduny, D.; Airey, J.A.; Singer, C.A.; Keller, P.S.; Shen, X.M.; Tian, H.; Valencik, M.; Hume, J.R. Orai1 interacts with STIM1 and mediates capacitative $\mathrm{Ca}^{2+}$ entry in mouse pulmonary arterial smooth muscle cells. Am. J. Physiol. Cell Physiol. 2010, 299, C1079-C1090. [CrossRef] [PubMed]

42. Li, J.; McKeown, L.; Ojelabi, O.; Stacey, M.; Foster, R.; O’Regan, D.; Porter, K.E.; Beech, D.J. Nanomolar potency and selectivity of a $\mathrm{Ca}^{2+}$ release-activated $\mathrm{Ca}^{2+}$ channel inhibitor against store-operated $\mathrm{Ca}^{2+}$ entry and migration of vascular smooth muscle cells. Br. J. Pharmacol. 2011, 164, 382-393. [CrossRef] [PubMed]

43. Dietrich, A.; Kalwa, H.; Storch, U.; Mederos y Schnitzler, M.; Salannova, B.; Pinkenburg, O.; Dubrovska, G.; Essin, K.; Gollasch, M.; Birnbaumer, L.; et al. Pressure-induced and store-operated cation influx in vascular smooth muscle cells is independent of TRPC1. Pflug. Arch. 2007, 455, 465-477. [CrossRef] [PubMed]

44. Saleh, S.N.; Albert, A.P.; Large, W.A. Obligatory role for phosphatidylinositol 4,5-bisphosphate in activation of native TRPC1 store-operated channels in vascular myocytes. J. Physiol. 2009, 587, 531-540. [CrossRef]

45. Albert, A.P.; Saleh, S.N.; Large, W.A. Inhibition of native TRPC6 channel activity by phosphatidylinositol 4,5-bisphosphate in mesenteric artery myocytes. J. Physiol. 2008, 586, 3087-3095. [CrossRef]

46. Imai, Y.; Itsuki, K.; Okamura, Y.; Inoue, R.; Mori, M.X. A self-limiting regulation of vasoconstrictor-activated TRPC3/C6/C7 channels coupled to PI(4,5)P2-diacylglycerol signalling. J. Physiol. 2012, 590, 1101-1119. [CrossRef]

47. Salamanca, D.A.; Khalil, R.A. Protein kinase C isoforms as specific targets for modulation of vascular smooth muscle function in hypertension. Biochem. Pharmacol. 2005, 70, 1537-1547. [CrossRef]

48. Kwon, Y.; Hofmann, T.; Montell, C. Integration of phosphoinositide- and calmodulin-mediated regulation of TRPC6. Mol. Cell 2007, 25, 491-503. [CrossRef]

49. Liu, M.; Large, W.A.; Albert, A.P. Stimulation of beta-adrenoceptors inhibits store-operated channel currents via a cAMP-dependent protein kinase mechanism in rabbit portal vein myocytes. J. Physiol. 2005, 562, 395-406. [CrossRef]

50. Albert, A.P.; Liu, M.; Large, W.A. Dual effect of calmodulin on store-operated Ca2+-permeable cation channels in rabbit portal vein myocytes. Br. J. Pharmacol. 2006, 148, 1001-1011. [CrossRef] 
51. Chen, I.S.; Dai, Z.K.; Welsh, D.G.; Chen, I.J.; Wu, B.N. Protein kinases modulate store-operated channels in pulmonary artery smooth muscle cells. J. Biomed. Sci. 2011, 18, 2. [CrossRef] [PubMed]

52. Logothetis, D.E.; Petrou, V.I.; Zhang, M.; Mahajan, R.; Meng, X.Y.; Adney, S.K.; Cui, M.; Baki, L. Phosphoinositide control of membrane protein function: A frontier led by studies on ion channels. Annu. Rev. Physiol. 2015, 77, 81-104. [CrossRef] [PubMed]

53. McLaughlin, S.; Wang, J.; Gambhir, A.; Murray, D. PIP 2 and proteins: Interactions, organization, and information flow. Annu. Rev. Biophys. Biomol. Struct. 2002, 31, 151-175. [CrossRef] [PubMed]

54. Gamper, N.; Shapiro, M.S. Target-specific PIP 2 signalling: How might it work? J. Physiol. 2007, 582, 967-975. [CrossRef] [PubMed]

55. Gallant, C.; You, J.Y.; Sasaki, Y.; Grabarek, Z.; Morgan, K.G. MARCKS is a major PKC-dependent regulator of calmodulin targeting in smooth muscle. J. Cell Sci. 2005, 118, 3595-3605. [CrossRef] [PubMed]

56. Quinn, K.V.; Behe, P.; Tinker, A. Monitoring changes in membrane phosphatidyylinositol 4,5-bisphoshate in living cells using a domain from the transcription factor tubby. J. Physiol. 2008, 586, 2855-2871. [CrossRef] [PubMed]

57. Balla, T.; Vamai, P. Visualization of cellular phosphoinositide pools with GFP-fused protein-domains. Curr. Protoc. Cell. Biol. 2009, 42. [CrossRef]

58. Szentpetery, Z.; Balla, A.; Kim, Y.J.; Lemmon, M.A.; Balla, T. Live cell imaging with protein domains vapable of recognizing phosphatidylinositol 4,5-bisphosphate; a comparative study. BMC Cell Biol. 2009, 10, 67. [CrossRef]

59. Balla, T. Phosphoinositides: Tiny lipids with giant impact on cell regulation. Physiol. Rev. 2013, 93, 1019-1137. [CrossRef]

60. Park, C.Y.; Shcheglovitov, A.; Dolmetsch, R. The CRAC channel activator binds and inhibits L-type voltage-gated calcium channels. Science 2010, 330, 101-105. [CrossRef]

61. Wang, Y.; Deng, X.; Mancarella, S.; Hendron, E.; Eguchi, S.; Soboloff, J.; Tang, X.D.; Gill, D.L. The calcium store sensor, STIM1, reciprocally controls Orai1 and CaV1.2 channels. Science 2010, 330, 105-109. [CrossRef] [PubMed]

62. Jousset, H.; Rrieden, M.; Demaurex, N. STIM1 knockdown reveals that store-operated $\mathrm{Ca}^{2+}$ channels located close to sarco/endoplasmic $\mathrm{Ca}^{2+}$-ATPases (SECRA) pumps silently refull the endoplasmic tecticulum. J. Biol. Chem. 2007, 282, 11456-11464. [CrossRef] [PubMed]

63. Ritchie, M.F.; Samakai, E.; Soboloff, J. STIM1 is required for attenuation of PMCA-mediated Ca ${ }^{2+}$ clearance during T-cell activation. EMBO J. 2012, 31, 1123-1133. [CrossRef] [PubMed]

64. Lefkimmiatis, K.; Srikanthan, M.; Maiellaro, I.; Moyer, M.P.; Curci, S.; Hofer, A.M. Store-operated cyclic AMP signalling mediated by STIM1. Nat. Cell Biol. 2009, 11, 433-442. [CrossRef] [PubMed]

65. Spassova, M.A.; Soboloff, J.; He, L.P.; Xu, W.; Dziadek, M.A.; Gill, D.L. STIM1 has a plasma membrane role in the activation of store-operated $\mathrm{Ca}^{2+}$ channels. Proc. Natl. Acad. Sci. USA 2006, 103, 4040-4045. [CrossRef] [PubMed]

66. Thompson, J.L.; Shuttleworth, T.J. Exploring the unique features of the ARC channel a store-operated Orai channel. Channels 2013, 7, 364-373. [CrossRef]

67. Yang, B.; Gwozdz, T.; Dutko-Gwozdz, J.; Bolotina, V.M. Orai1 and Ca ${ }^{2+}$-independent phospholipase A2 are required for store-operated Icat-SOC current, $\mathrm{Ca}^{2+}$ entry, and proliferation of primary vascular smooth muscle cells. Am. J. Physiol. Cell Physiol. 2012, 302, C748-C756. [CrossRef]

68. Bolotina, V.M. Orai, STIM1 and iPLA 2 beta: A view from a different perspective. J. Physiol. 2008, 586, 3035-3042. [CrossRef]

69. Avila-Medina, J.; Calderón-Sánchez, E.; González-Rodríguez, P.; Monje-Quiroga, F.; Rosado, J.A.; Castellano, A.; Ordonez, A.; Smani, T. Orai1 and TRPC1 Proteins Co-localize with CaV1.2 Channels to Form a Signal Complex in Vascular Smooth Muscle Cells. J. Biol. Chem. 2016, 291, 21148-21159. [CrossRef]

70. Avila-Medina, J.; Mayoral-Gonzalez, I.; Dominguez-Rodriguez, A.; Gallardo-Castillo, I.; Ribas, J.; Ordonez, A.; Rosado, J.A.; Smani, T. The Complex Role of Store Operated Calcium Entry Pathways and Related Proteins in the Function of Cardiac, Skeletal and Vascular Smooth Muscle Cells. Front. Physiol. 2018, 9, 257. [CrossRef]

71. Chakraborty, S.; Berwick, Z.C.; Bartlett, P.J.; Kumar, S.; Thomas, A.P.; Sturek, M.; Tune, J.D.; Obukhov, A.G. Bromoenol lactone inhibits voltage-gated $\mathrm{Ca}^{2+}$ and transient receptor potential canonical channels. J. Pharmacol. Exp. Ther. 2011, 339, 329-340. [CrossRef] [PubMed] 
72. Saleh, S.N.; Albert, A.P.; Large, W.A. Activation of native TRPC1/C5/C6 channels by endothelin-1 is mediated by both $\mathrm{PIP}_{3}$ and $\mathrm{PIP}_{2}$ in rabbit coronary artery myocytes. J. Physiol. 2009, 587, 5361-5375. [CrossRef] [PubMed]

(ㄷ) (1)

(C) 2020 by the authors. Licensee MDPI, Basel, Switzerland. This article is an open access article distributed under the terms and conditions of the Creative Commons Attribution (CC BY) license (http://creativecommons.org/licenses/by/4.0/). 